\title{
A percepção do usuário no ambiente construído em relação a evacuação emergencial de locais de grande público: o caso dos terminais de passageiros
}

\section{The user's perception of the built environment in relation to the emergency evacuation of public places: the case of passenger terminals}

DOUGLAS DE CASTRO BROMBILLA Mestre, Instituto Federal de Educação, Ciência e Tecnologia do Rio Grande do Sul - IFRS, douglas.brombilla@riogrande.ifrs.edu.br

LIZANDRA GARCIA LUPI VERGARA

Doutora, Universidade Federal de Santa Catarina - UFSC, lizandravergara@gmail.com

JOÃO CARLOS SOUZA

Doutor, Universidade Federal de Santa Catarina - UFSC, joao.carlos@ufsc.br

\begin{abstract}
RESUMO
Ao investigar os acidentes em locais de grande público, várias lacunas são identificadas como o comportamento das multidões e principalmente problemas na orientação dos usuários em uma situação de emergência. Portanto, o objetivo desse trabalho foi desenvolver uma avaliação da evacuação emergencial de um terminal de passageiros, levando em consideração a forma arquitetônica adotada e a percepção do usuário em relação a orientação no ambiente construído. A hipótese é que, além da existência de rotas de fuga convenientemente dimensionadas, um dos principais fatores que dificultam a evacuação emergencial de locais de grande público é a falta de conhecimento prévio do espaço pelos usuários. Desta forma, a percepção do ambiente auxilia o usuário na tomada de decisão para se evadir do local no momento de uma emergência. Para a fundamentação do trabalho foi realizada uma revisão bibliográfica sobre: comportamento das multidões e orientação espacial. A metodologia escolhida foi a exploratória (qualitativa), com a aplicação de métodos distintos como a visita exploratória e entrevistas semiestruturadas. Os resultados foram parcialmente confirmados, conforme a hipótese. Ficou evidente que a sinalização para rotas de fugas não é eficiente no ponto de vista dos usuários e que o conhecimento prévio do local não é um fator preponderante. Pode-se afirmar que o ambiente construído influencia na tomada de decisão dos usuários, que tentam se localizar ou agir, conforme as suas percepções
\end{abstract}

PALAVRAS-CHAVE: Ambiente construído, Percepção ambiental, Segurança 


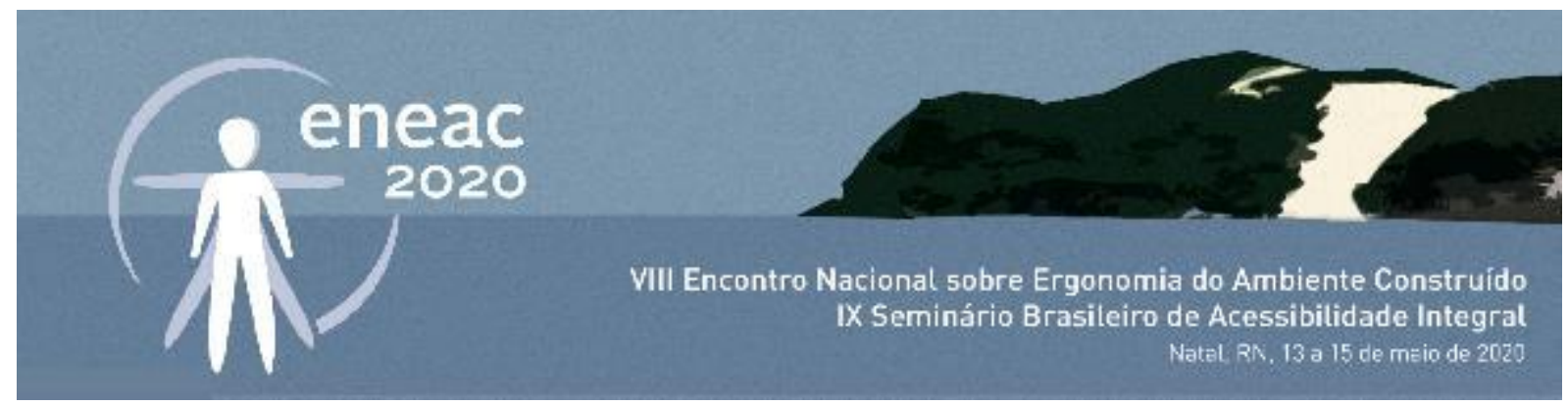

\begin{abstract}
When investigating accidents in public places, several gaps are identified as the behavior of the crowds and mainly problems in guiding users in an emergency situation. Therefore, the objective of this work was to develop an assessment of the emergency evacuation of a passenger terminal, taking into account the architectural form adopted and the user's perception of the orientation in the built environment. The hypothesis is that, in addition to the existence of conveniently dimensioned escape routes, one of the main factors that hinder the emergency evacuation from public places is the lack of previous knowledge of the space by users. In this way, the perception of the environment assists the user in making a decision to escape from the place at the time of an emergency. To support the work, a bibliographic review was carried out on: crowd behavior and spatial orientation. The chosen methodology was exploratory (qualitative), with the application of different methods such as the exploratory visit and semi-structured interviews. The results were partially confirmed, according to the hypothesis. It was evident that the signs for escape routes are not efficient from the users' point of view and that prior knowledge of the location is not a major factor. It can be said that the built environment influences the decision making of users, who try to locate or act, according to their perceptions
\end{abstract}

KEYWORDS: Built environment, Environmental perception, Security

\title{
1 INTRODUÇÃO
}

A partir dos variados acidentes ocorridos em locais de grande concentração de público, identificou-se que os espaços como boates, shopping, estádios de futebol entre outros possuem várias lacunas, sendo uma delas no que se refere ao comportamento humano das multidões. Segundo Valentin e Ono (2006) o ser humano diante de uma situação de emergência, independentemente de sua experiência anterior, idade, sexo ou treinamento, toda pessoa envolvida em uma situação de emergência sentirá algum estresse. Portanto, quanto mais orientado o usuário estiver no espaço mais rápido ele poderá tomar a decisão em uma situação de emergência.

Este estudo destaca como relevante, além dos itens citados em norma, avaliar como o usuário orienta-se no ambiente construído, principalmente em uma situação de emergência. $O$ usuário estando bem orientado no ambiente, poderá minimizar uma possível situação de pânico, já que os mesmos em determinados locais não possuem um treinamento prévio. Dessa forma o trabalho se propõem a avaliar o desempenho através do ponto de vista do usuário (tomada de decisão) levando em consideração o ambiente construído Terminal de Passageiros, avaliando o seu desempenho no que se refere a evacuação emergencial.

Conforme Brombilla (2014), para termos uma evacuação emergencial com segurança e com tempo de resposta ideal, devemos ter uma Gestão de Riscos, que leve em consideração os seguintes pontos: Treinamento e capacitação de funcionários, plano de emergência e contingência, projetos e edificações conforme normas e suas particularidades e o comportamento humano (Figura 1). 


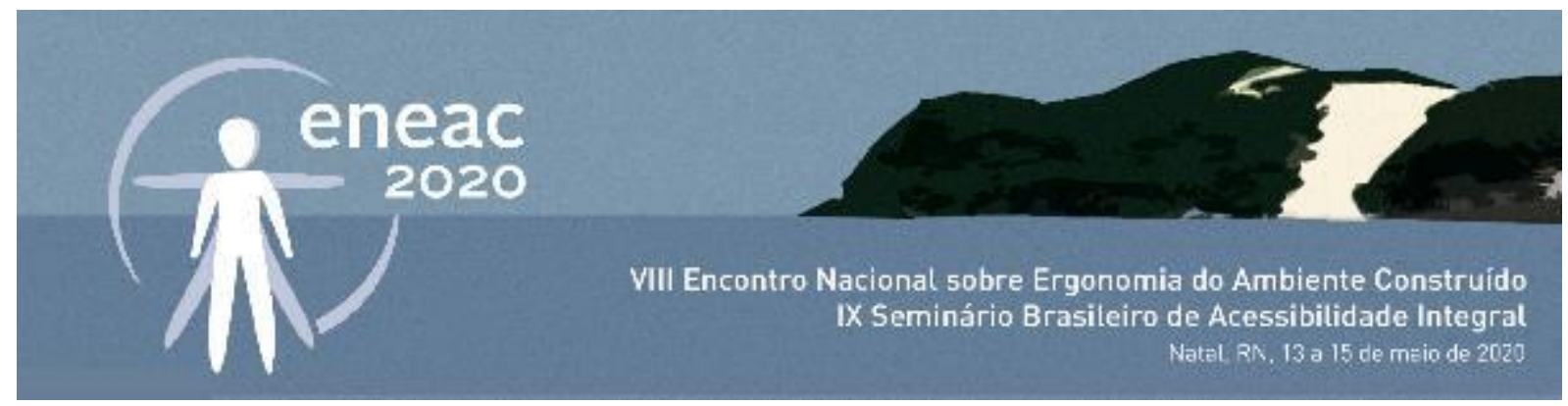

Figura 1:

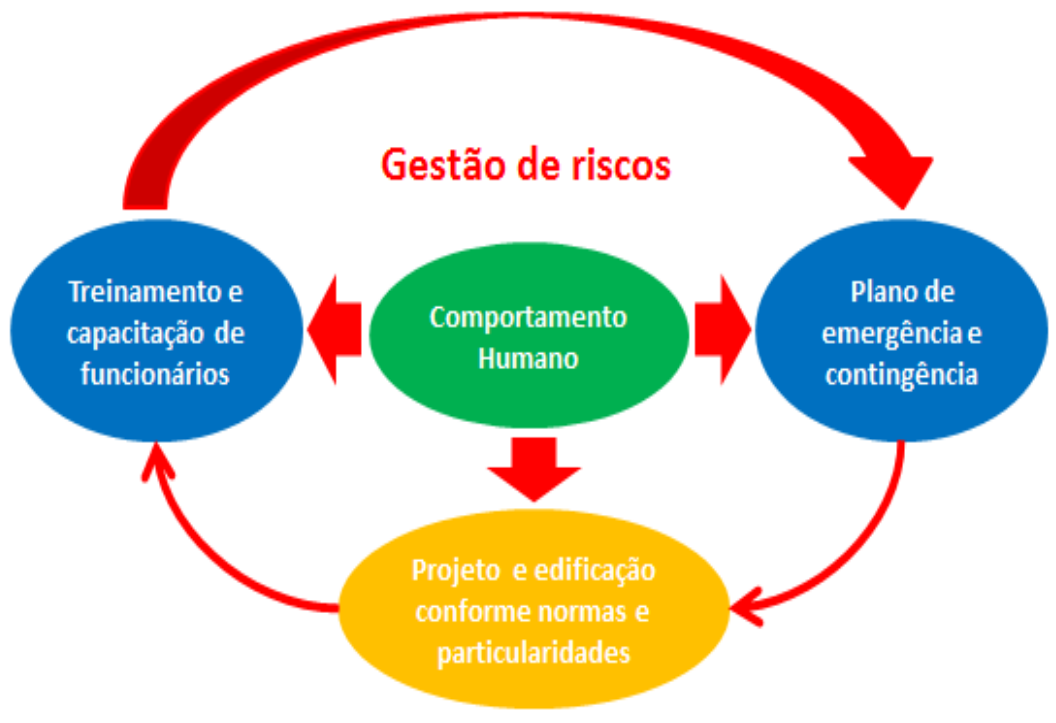

Fonte: Brombilla (2014)

A escolha do Terminal de Passageiros, se dá por ser um local de grande concentração de público, e seus usuários não serem fixos. Não se sabe a quantidade de vezes que cada um dos usuários já frequentou o local, o que dificulta as instruções de emergência e principalmente a informação/treinamento.

A Hipótese é que, além da existência de rotas de fuga convenientemente dimensionadas, um dos principais fatores que dificultam a evacuação emergencial de locais de grande público é a falta de conhecimento prévio do espaço pelos usuários. Desta forma, a percepção do ambiente auxilia o usuário na tomada de decisão para se evadir do local no momento de uma emergência.

O objetivo desse trabalho foi desenvolver uma avaliação da evacuação emergencial de um Terminal de passageiros, levando em consideração a forma arquitetônica adotada e a percepção do usuário em relação a orientação no ambiente construído.

\section{REFERENCIAL TEÓRICO}

Para o desenvolvimento desse trabalho, foi necessário o aprimoramento teórico de temas como comportamento das multidões e orientação espacial. Os principais dados extraídos dessa revisão estão expostos a seguir de forma sucinta.

\section{Comportamento das multidões}

O comportamento das multidões chama a atenção pelos registros feitos no acidentes ocorridos, onde muitas pessoas morreram pisoteadas ou sufocadas ou, ainda, acabaram se deslocando para locais não indicados em situações de emergência. 


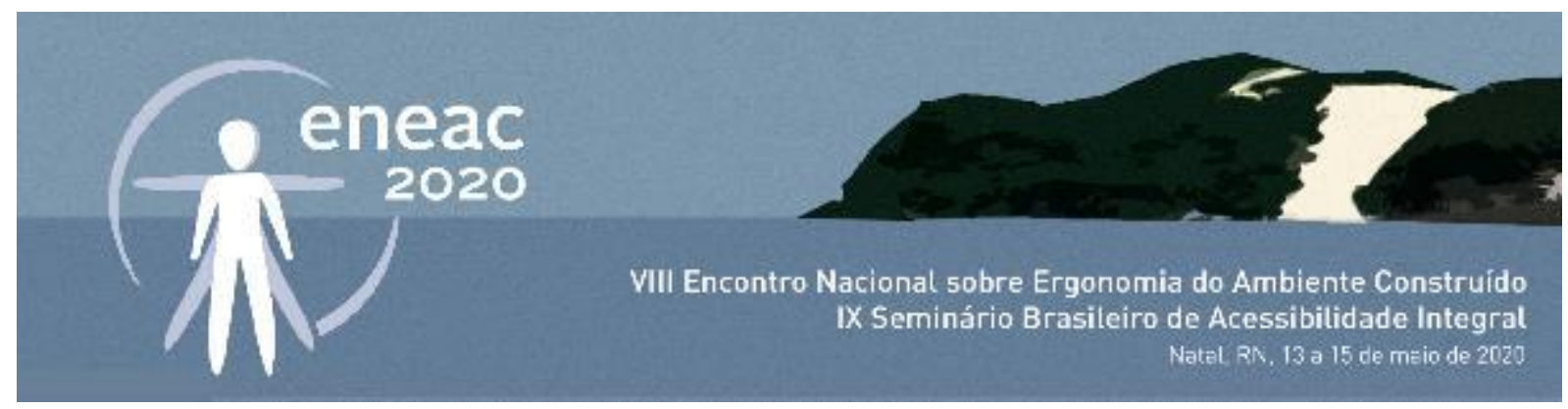

Conforme Alves (2011), em um situação de pânico em multidões, as pessoas percebem que a sobrevivência é um produto de tomadas de decisões e que a personalidade individual é enfraquecida. Nessas horas as pessoas assumem um comportamento imitativo onde acontecem palavras de ordem que reforçam a identidade grupal em detrimento do individual. Desta forma as pessoas se manifestam de forma irracional, preocupadas com a ideia de fugir e não consideram as consequências de seus atos.

Sendo assim, as pessoas tentam se auto preservar, mas muitas vezes esse instinto leva a cometer erros por não pensar de forma racional. Isso poderia ser minimizado com treinamentos e orientações espaciais capazes de não gerar dúvida na hora de uma evacuação.

\section{Orientação espacial}

Esse termo apareceu primeiramente na arquitetura no início dos anos 60 através do livro "A imagem da cidade" do Arquiteto Kevin Lynch, que definia a orientação da seguinte forma:

No processo de orientação, o elo estratégico é a imagem do meio ambiente, a imagem metal generalizada do mundo exterior que o indivíduo retém. Esta imagem é o produto da percepção imediata e da memória da experiência passada e ela está habilitada a interpretar informações e a comandar ações”. (Lynch, 1960 p. 14)

A acessibilidade espacial é definida por Dischinger et. al (2012), por quatro componentes, descritos dessa forma: orientação espacial, comunicação, deslocamento e uso. O componente de orientação espacial significa características dos ambientes, que permitem, aos indivíduos, reconhecer a identidade e as funções dos espaços, saber onde estão e definir estratégias para seu deslocamento.

Outro conceito importante voltado a orientação é o Wayfinding, que realizando a tradução para língua portuguesa seria o planejamento de rota a partir de uma posição do usuário, que vai determinar a sua orientação e deslocamento no ambiente construído. Segundo Abrams (2010) o Wayfinding é comumente utilizado na arquitetura, referindo-se à orientação do usuário e à seleção de um caminho a ser percorrido. Adições modernas ao termo agora abrangem uma série de elementos de design arquitetônico que auxiliam na orientação.

A Orientação espacial é um dos componente importante da acessibilidade espacial. Uma edificação sem uma boa orientação espacial dificulta aos usuário na sua localização, o que poderá acarretar uma maior dificuldade como por exemplo na evacuação em locais de grande público, por esse motivo a importância de relacionar esse assunto com o trabalho.

\section{OBJETO DE ESTUDO}

A pesquisa foi desenvolvida no Terminal rodoviário da cidade de Pelotas - RS (ETERPEL), localizado na Avenida Presidente João Goulart, 4605 no Bairro Fragata (Figura 2). 

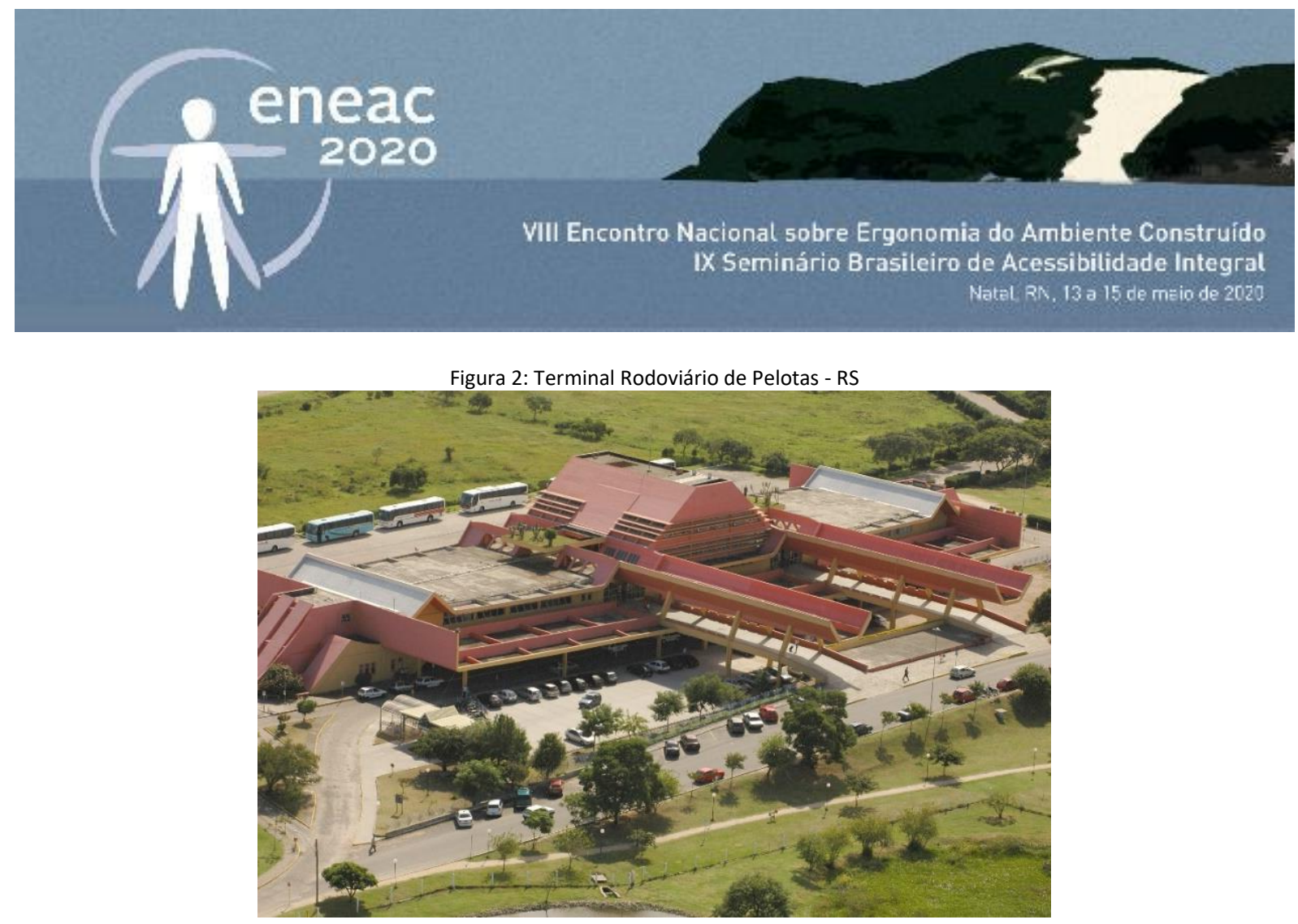

Fonte: http://www.rodoviariapelotas.com.br/institucional/estrutura

O terminal teve a sua inauguração no ano de 1984. Aproximadamente 2700 usuários o utilizam diariamente e, nos dias de maior concentração como feriados e dias próximos ao final de semana (segundas e sextas), transitam aproximadamente 3200 usuários/dia. O edifício é constituído de um pavimento térreo e mais dois pavimentos. No térreo funcionam os serviços (lancheiras e lojas) e o setor de embarque do terminal. No 10 pavimento fica a venda de passagens, shopping de lojas locais e local de espera. 0 2o pavimento e utilizado pela administração do Terminal.

\section{METODOLOGIA}

Para o desenvolvimento do trabalho, optou-se por adotar uma metodologia exploratória (qualitativa). Para a realização deste estudo foram utilizados métodos distintos como a visita exploratória e entrevistas semiestruturadas.

A revisão bibliográfica auxiliou na estruturação e na base do referencial teórico do trabalho. A visita exploratória se fez necessária para o registro do espaço construído quanto às condições de evacuação emergencial, sob a visão do técnico/pesquisador a partir das técnicas de medições e registros fotográficos. Para o tratamento dos resultados será utilizado proposta de análise de conteúdo conceituada por Bardin (2011).

\section{Visita exploratória}

Na visita foram detectados dois problemas no layout do prédio. Primeiro, foi a rampa helicoidal, que não tem inclinação ideal, não possui corrimão em duas alturas e nem piso tátil de alerta no início e no fim (Figuras 3 e 4). Conforme a sinalização, esta rampa poderia ser usada como rota de fuga, o que acarretaria em um risco para os usuários. 


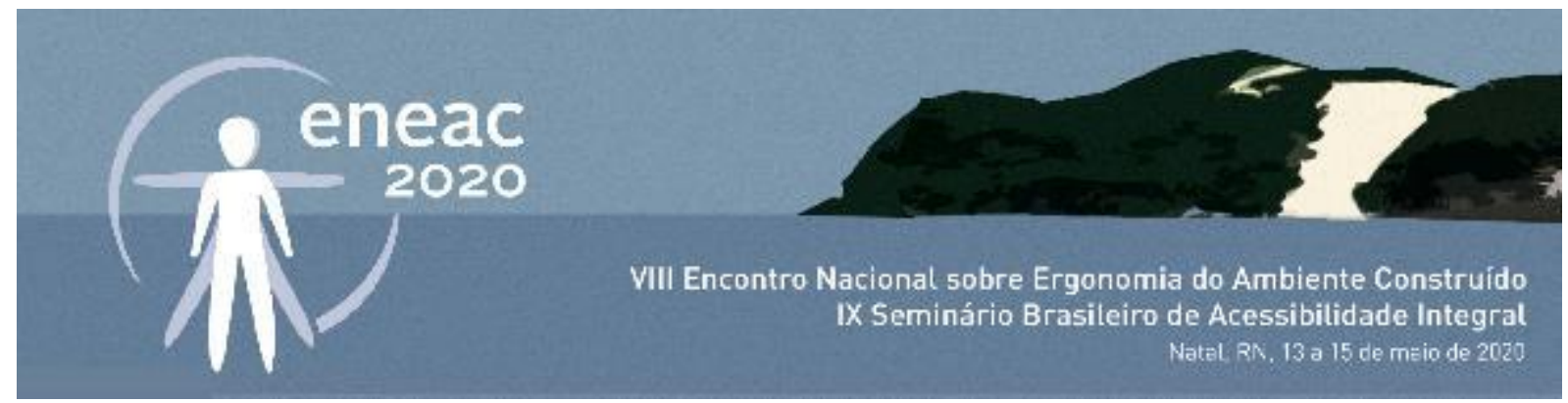

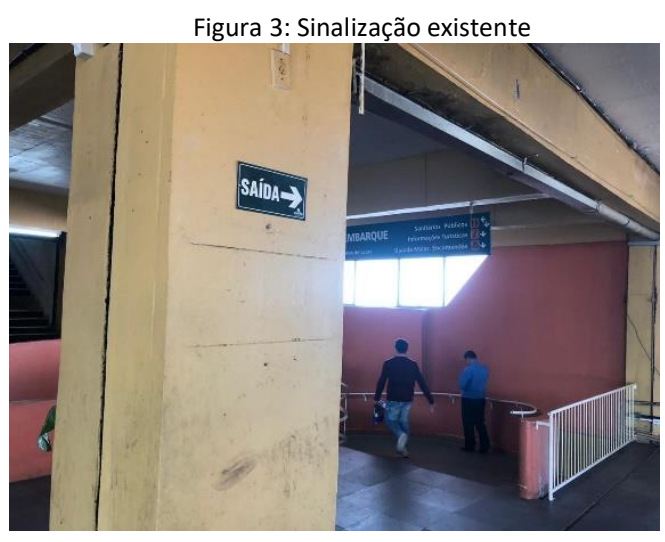

Fonte: Autores. 2019

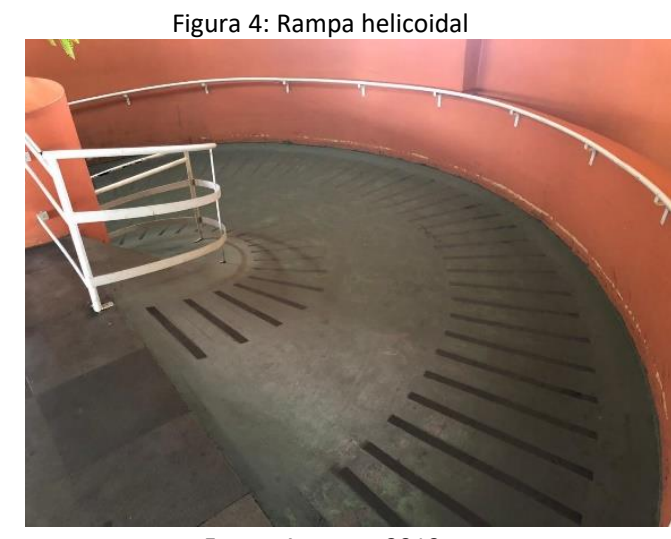

Fonte: Autores. 2019

O segundo problema, seriam as portas do pavimento térreo que dão acesso à área externa e possuem abertura através de sensores de presença, que numa situação de emergência poderão ter o seu funcionamento comprometido em virtude de um possível corte de energia (Figura 5). Situação que não se repete nas portas do 10 pavimento, onde o seu funcionamento é manual e permanecem sempre abertas durante o funcionamento do terminal (Figura 6).

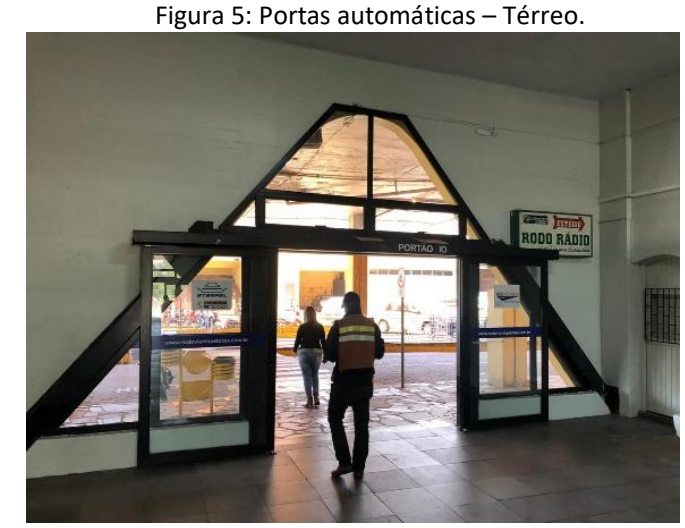

Fonte: Autores. 2019

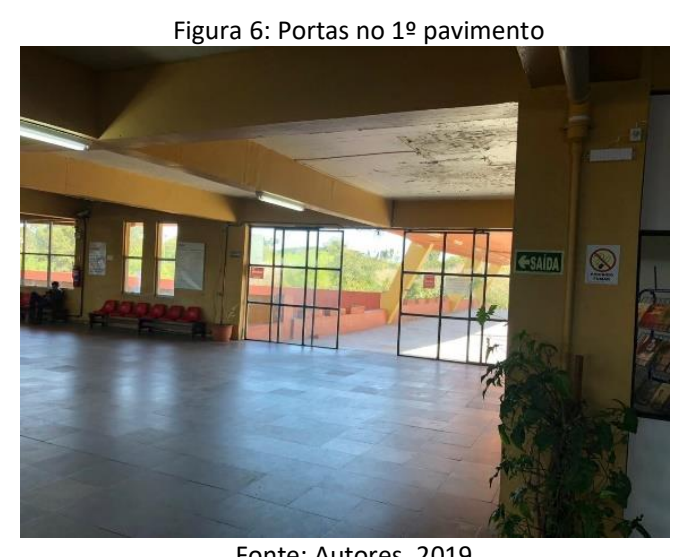

Fonte: Autores. 2019

Os pontos positivos são as dimensões das saídas, pois são amplas e são bem marcadas na edificação (Figura 7). Outro ponto positivo e a escada existente (Figura 8), que poderá ser utilizada como rota de fuga, mas poderia ter uma sinalização mais efetiva que deixasse claro que a sua utilização deve ser prioridade em relação as rampas existentes. 


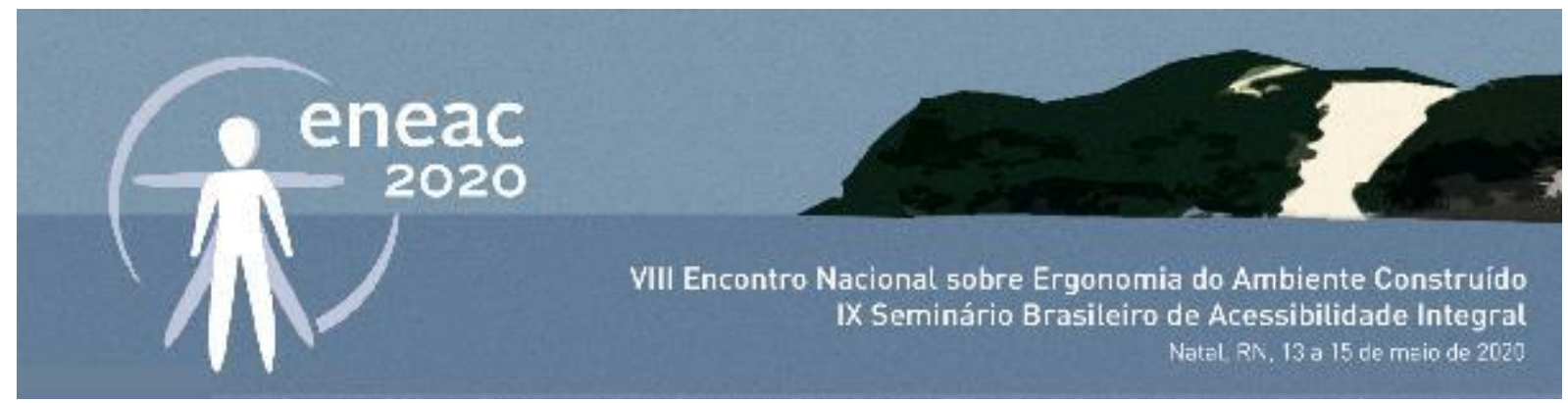

Figura 7: Entradas superiores - 10 Pavimento

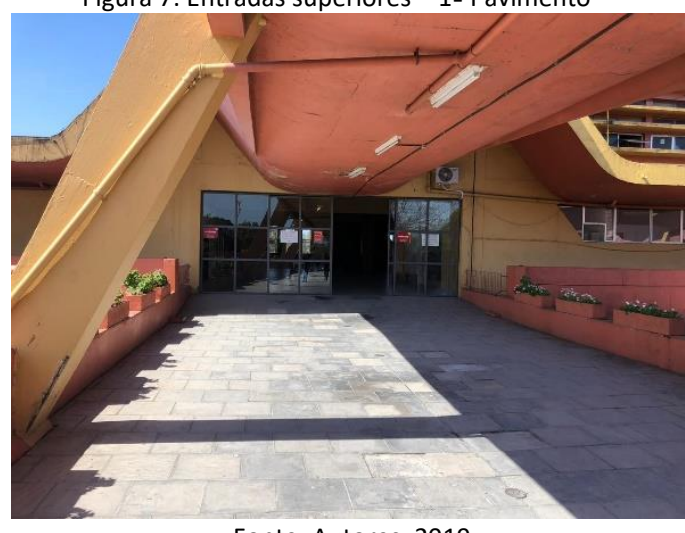

Fonte: Autores. 2019

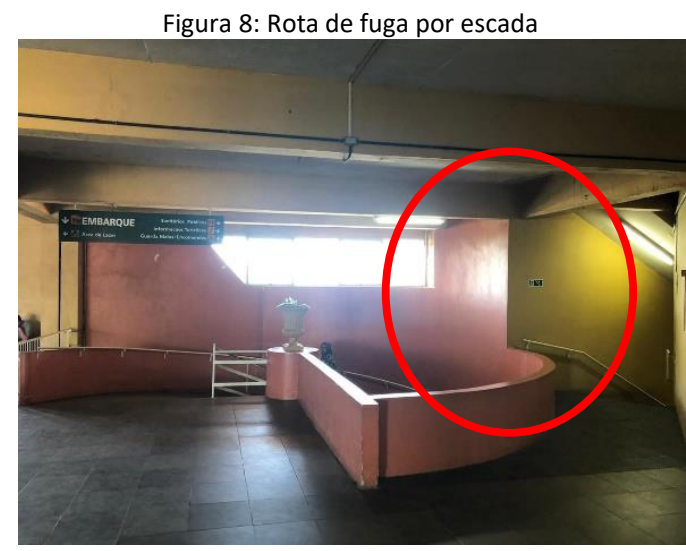

Fonte: Autores. 2019

\section{Entrevistas Semiestruturadas}

Como optou-se pelo processo simplificado de análise de conteúdo, descrito por Guerra (2012) através da proposta de Poirier e Valladon (1983), que no qual a proposta tem como número razoável de entrevistas de pelo menos 15 a 20 entrevistas, que consiste nas transcrições e leitura das entrevistas, construção das sinopses, análise descritiva e interpretativa, foram realizadas 15 entrevistas com usuários do Terminal Rodoviário.

A entrevista constou com o preenchimento de dados para a caracterização da amostra e 4 perguntas divididas em duas categorias: orientação espacial e segurança, conforme abaixo no roteiro das entrevistas aplicadas (Figura 9). Na etapa de construção da sinopse foram definidas as temáticas e as problemáticas.

Figura 9: Questionário aplicado

\begin{tabular}{|c|c|c|c|c|}
\hline \multicolumn{5}{|c|}{ ROTEIRO DE ENTREVISTA SEMI-ESTRUTURADA COM PASSAGEIROS } \\
\hline LOCAL: & \multicolumn{2}{|l|}{ DATA: } & \multicolumn{2}{|l|}{ HORARIO: } \\
\hline \multicolumn{3}{|l|}{ NOME: } & \multicolumn{2}{|c|}{ IDADE: } \\
\hline GEENERO: & \multicolumn{4}{|l|}{ PROFISSÄO: } \\
\hline \multicolumn{5}{|c|}{$\begin{array}{l}\text { OBJETTVO DA PESQUTSA: Avaliar a percepção do usuário no ambiente construído em relação a evacuação } \\
\text { emergencial (situação de emergência) }\end{array}$} \\
\hline COM QUE FREQUENNCIA CIRCULAS PELO ESPAC̣O? & Diariamente & Semanalmente & Mensalmente & Eventualmente \\
\hline
\end{tabular}

1. Saberias identificar uma rota de fuga observando a sinalização existente? Em caso positivo, explique como.

2. Numa situação de emergência, quais informações buscarias na sinalização?

\section{SEGURANÇA}

Com relação ao espaço construído, você se sentiria seguro para abandonar esse local? Em caso positivo, justifique e esclareça os motivos que levam a isso.

4. O que você faria em uma situação de emergência? 


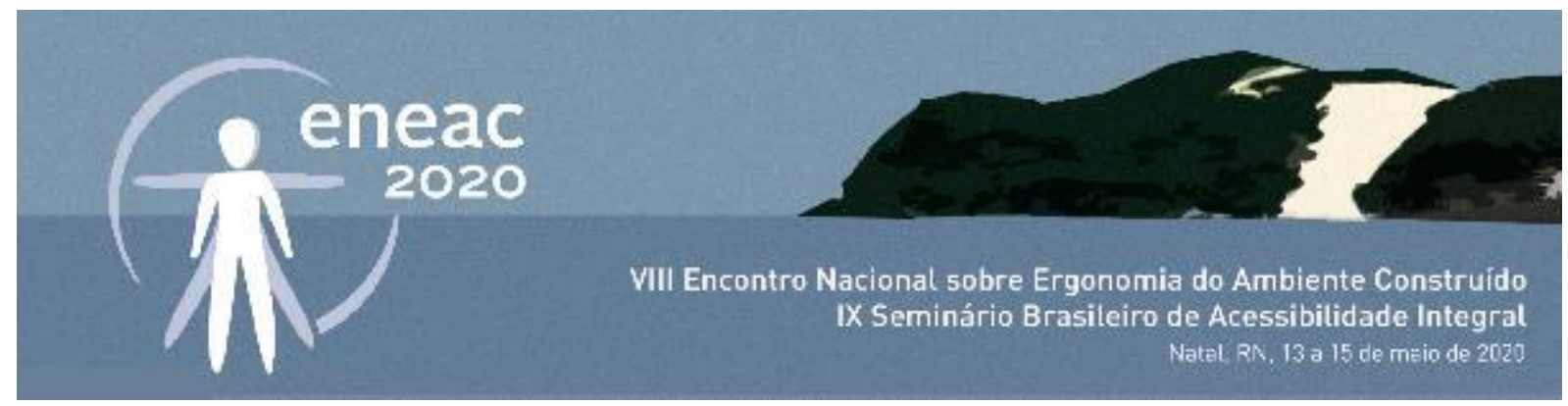

A pesquisa foi encaminhada para Comitê de Ética em Pesquisas com Seres Humanos da Universidade Federal de Santa Catarina (UFSC) e aprovada através do parecer número 3.523.438. Os participantes foram selecionados de forma aleatória no terminal e convidados a realizar a entrevista na qual assinaram o Termo de Consentimento Livre e Esclarecido, concordando em participar da amostra como voluntários, de forma confidencial e anônima. Todas as entrevistas com os usuários foram gravadas e transcritas para a realização da análise de conteúdo.

\section{RESULTADOS}

Após a realização das entrevistas e os tratamentos dos dados, podemos observar que os usuários de espaços públicos possuem muitas dúvidas no que se refere a percepção espacial no que se trata de evacuação emergencial.

\section{Caracterização da amostra}

A pesquisa foi realizada com um grupo de 15 entrevistados com perfis diversificados (tabela 1), pois foi uma abordagem aleatória no terminal em estudo. Conforme a pesquisa, foram criados grupos de faixa etária para melhor distribuir os dados da seguinte forma: de 15 à 30 anos, de 30 à 50 anos, acima de 50 anos e também grupos referente a frequência que o entrevistado utiliza o espaço sendo eles: Eventualmente, semanalmente ou mensalmente. Outras informações coletadas foram o gênero e a profissão.

Tabela 1: Caracterização da amostra

\begin{tabular}{|c|c|c|c|c|}
\hline Entrevistado & Faixa Etária & Gênero & Profissão & Frequência no espaço \\
\hline E.01 & 18 & Masculino & Jogador de Futebol & Eventualmente \\
\hline E.02 & 22 & Masculino & Laboratorista & Eventualmente \\
\hline E.03 & 49 & Masculino & Supervisor de vendas & Semanalmente \\
\hline E.04 & 22 & Feminino & Estudante & Eventualmente \\
\hline E.05 & 63 & Feminino & Professora & Eventualmente \\
\hline E.06 & 71 & Masculino & Professor & Mensalmente \\
\hline E.07 & 68 & Feminino & Aposentada & Mensalmente \\
\hline E.08 & 25 & Masculino & Professor & Eventualmente \\
\hline E.09 & 35 & Masculino & Autônomo & Eventualmente \\
\hline E.10 & 43 & Masculino & Professor & Semanalmente \\
\hline E.11 & 24 & Masculino & Estudante & Eventualmente \\
\hline E.12 & 33 & Masculino & Pedreiro & Eventualmente \\
\hline E.13 & 18 & Feminino & Estudante & Eventualmente \\
\hline E.14 & 61 & Feminino & Do lar & Eventualmente \\
\hline E.15 & 24 & Feminino & Desempregada & Semanalmente \\
\hline
\end{tabular}




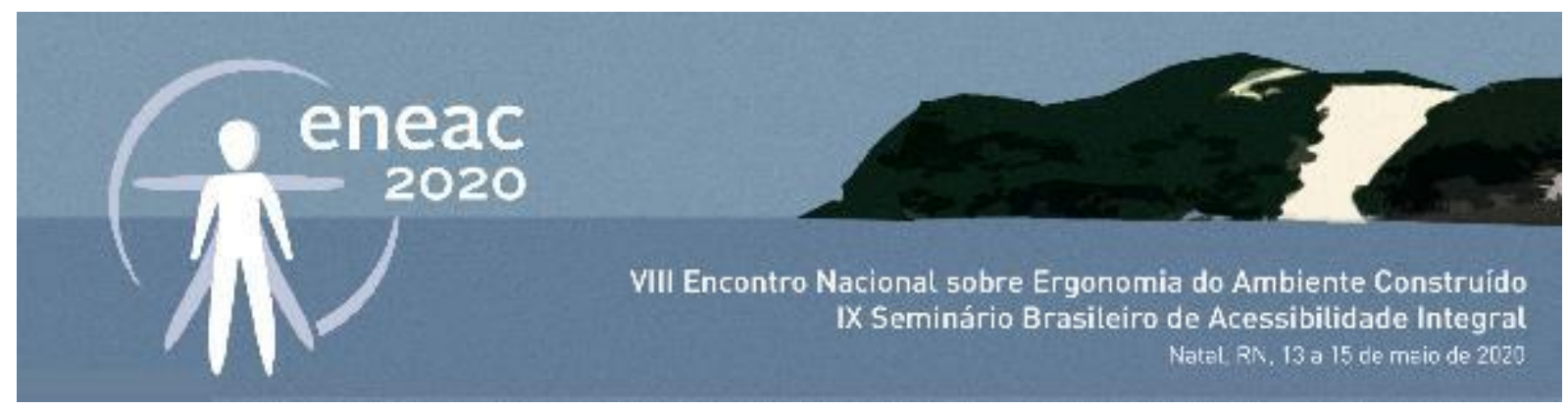

Segundo Ono (2018) para entender a desorientação espacial [...] é fundamental a compreensão das características das populações usuárias do ambiente construído em questão, como número de usuários frequentes e visitantes ocasionais, horários de acesso, faixa etária e características socioeconômicas, sempre à luz de aspectos de acessibilidade e do desenho universal". Conforme os entrevistados, podemos caracterizar a população da seguinte forma: $60 \%$ dos entrevistados são do sexo masculino; a faixa etária de maior concentração é de $46 \%$ e fica entre 15 e 30 anos; a maioria dos usuários utilizam o Terminal de forma eventual somando 67\%; a profissão dos entrevistados é bem diversificada somando a maior de professores, no total 4 entrevistados.

\section{Percepção dos entrevistados}

Conforme já apresentado na metodologia, o roteiro das entrevistas foram separadas em categorias, divididas com os seguintes temáticas: orientação espacial e segurança.

Na pergunta relacionada a identificação de rotas de fugas (orientação espacial) através da sinalização existente, ficou evidente que a sinalização não é efetiva para a identificação e que os usuários possuem dificuldades em identificar as rotas através das placas. Como define Dischinger et. al (2012), a orientação espacial significa características dos ambientes, que permitem, aos indivíduos, reconhecer a identidade e as funções dos espaços, saber onde estão e definir estratégias para seu deslocamento.

Os usuários relataram que são poucas placas de sinalização e as informações contidas são pequenas, conforme relato do entrevistado 07 "... Eu to achando que não, acho que não. Não tem muita sinalização..." e o entrevistado 01 relata que "...olhando só aquelas plaquinhas diria que não...". Os entrevistados 03, 08 e 13 relataram que pela sinalização não localizam as rotas, mas por terem conhecimento prévio do prédio saberiam localizar as rotas existentes, segundo o entrevistado 03 "...Não, pela sinalização não, mas pelo meu conhecimento do prédio, sim...". Podemos definir que o local não possui uma boa orientação espacial no sentido de orientar os usuários em uma situação de emergência ou no mínimo é insuficiente para orientar de forma efetiva os usuários do espaço.

Quando questionados sobre que informações procurariam nas sinalizações (orientação espacial), 73\% entrevistados destacaram a busca pela informação das setas indicativas, conforme o relato do entrevistado 02 "... A seta.... Eu acho que é a palavra-chave, não sei seria essa a... seria a seta que indica a direção...". Um dos entrevistados citou o bonequinho correndo, isso reforça a importância da utilização de simbologias ou pictogramas nas placas de orientação espacial. Conforme Ranoya et. al (2012) definem que os [...] os pictogramas que, por meio de imagens simplificadas, reforçam o sentido de mensagens verbais ou as traduzem de um modo mais "divertido", emotivo, que colabora com sua rápida e correta interpretação por parte dos usuários/ receptores/atores sociais. 0 entrevistado 10 mencionou que "... teria que ter algo visível para todos, eu posso ter uma perspicácia que eu consiga achar uma rota de fuga, mas outras pessoas poderiam ter mais dificuldade de achar...". Esse relato fica clara a preocupação com usuários com algum tipo de deficiência ou com algum tipo de dificuldade de interpretação.

Na terceira pergunta os entrevistados foram questionados sobre o percepção ambiental do prédio, no sentido de estar seguro para abandonar o local levando em consideração o espaço construído (segurança), 67 \% os usuários consideram o local favorável para uma evacuação emergencial, conforme a espacialidade do prédio. 0 entrevistado 11 relata que "...Bom, até que sim... Porque tem duas grandes saídas bem aberta, né...". Conforme a visita exploratória, verificou-se que as saídas são 


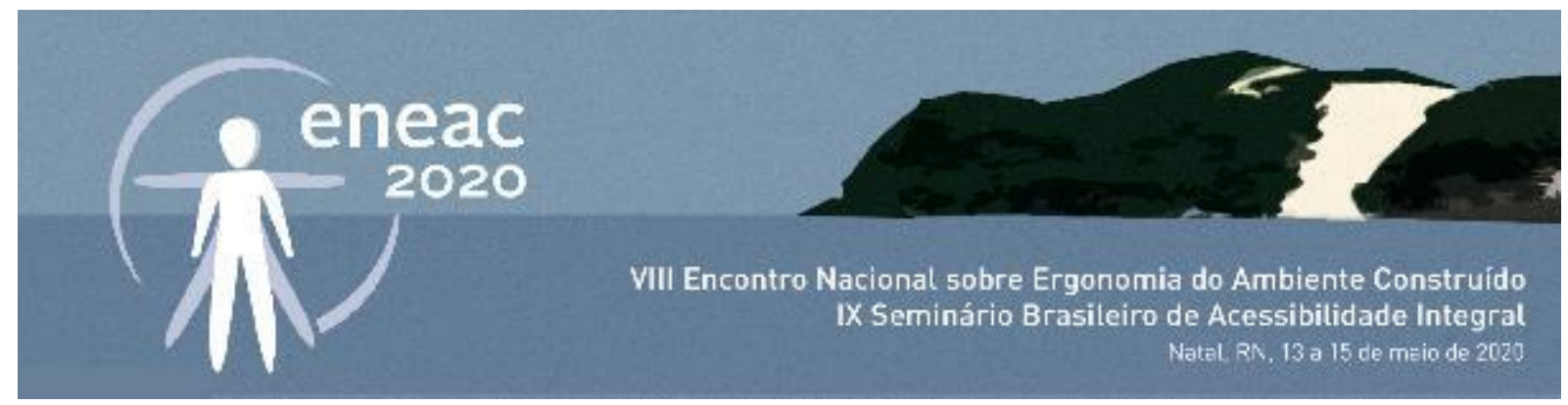

amplas, mas o pé direto baixo e a pouca luminosidade podem dificultar as tomadas de decisões no espaço (Figura 10).

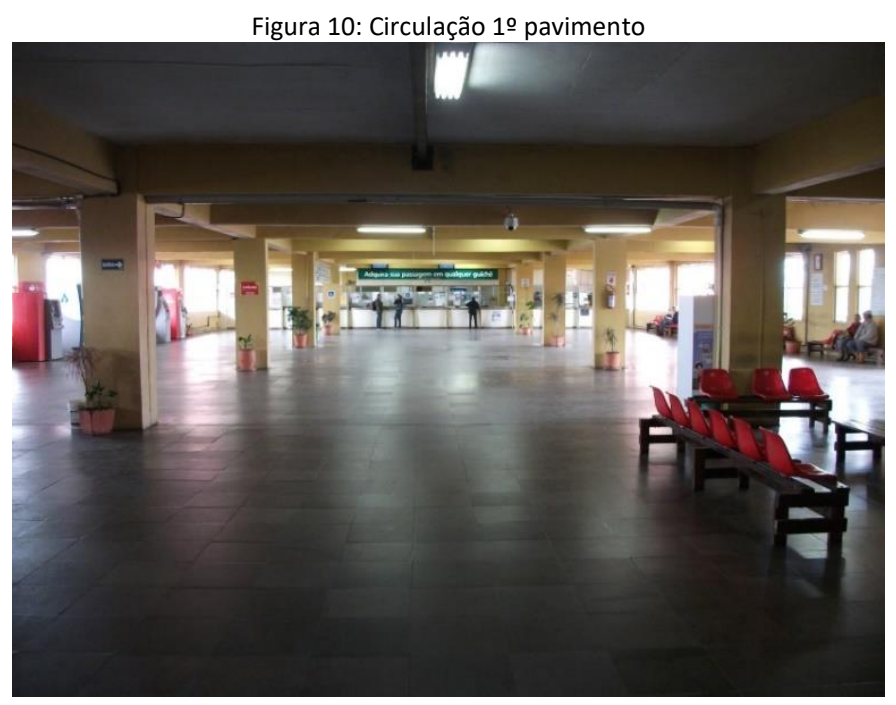

Fonte: http://www.rodoviariapelotas.com.br/institucional/estrutura

Alguns relatos diferenciaram os dois pavimentos do terminal, como o entrevistado 06 que fez a seguinte colocação "...Acho que aqui em cima sim, porque aqui tem duas rotas de fuga grande, mas acho que lá em baixo, eu acho lá em baixo mais fechado...". Essa percepção também ocorreu de forma contraria, colocando o 10 pavimento como mais fechado e a parte térrea mais aberta, conforme o relato do entrevistado 13 "...Acho que não risos... Acho que aqui em cima, não sei, acho que até lá embaixo é mais fácil...". Essa contradição acontece pela percepção espacial dos usuários. 0 que podemos evidenciar que dependendo onde estiver o usuário, a percepção espacial poderá influenciar na tomada de decisão no momento de uma emergência.

Conforme Souza (2015 p. 30 apud Carlson, 2002) a percepção cerebral é classificada em sete tipos: a visual, auditiva, olfativa, gustativa e tátil, além da percepção temporal e espacial. A percepção espacial leva em consideração a estimativa das distâncias entre os objetos e o tamanho relativo e também é considerada como supra modal, pois utiliza elementos da percepção auditiva, visual e temporal.

Através dos relatos, fica evidenciada a relação entre o comportamento e a percepção do ambiente está vinculada aos atributos do ambiente físico. Segundo Wohlwill (1970), essa relação se distingue de três formas: reações afetivas e "atitudinais" diante de características ambientais; reações de aproximação e esquiva diante de atributos do ambiente e adaptação às qualidades ambientais.

Quando se entra na problemática do comportamento humano (segurança), começa-se a tratar da pergunta relacionada a atitude individual de cada um dos entrevistados em uma situação de emergência. Para melhor tratamento dos resultados, as entrevistas foram divididas em 3 problemáticas: observar, ajudar ou em pânico. Entre os entrevistados, 9 responderam que iriam observar a situação antes de agir, como o entrevistado 02 "... Analisaria primeiramente se é 


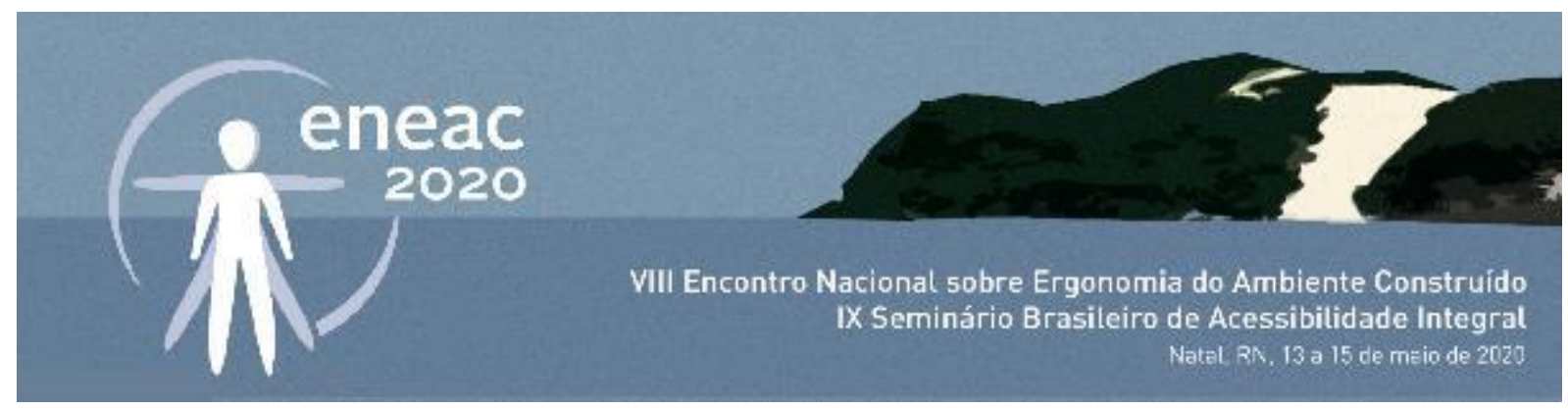

realmente uma emergência, eu teria certeza da situação..." e 6 responderam que ajudariam outras pessoas, se na hora isso fosse possível. Dentre essas 6 pessoas, 5 são entrevistados que estão entre os 9 que observariam a situação antes de agir.

No caso, o mesmo entrevistado 02 relatou "... eu buscaria pessoas que não perceberam que é uma emergência ainda e ajudaria elas a sair...". Os entrevistados que causam maior preocupação são os que retrataram que ficariam em pânico em um momento de emergência.

Essa situação de pânico preocupa, pois esses usuários terão muitas dificuldades no momento de uma emergência. Dentre os entrevistados, somente 5 relataram essa situação, isso significa $25 \%$ da amostra. Surgiram os seguintes relatos: entrevistado 15 "... Ficaria paralisada, no momento do nervosismo eu não consigo agir, eu travo! risos...", o entrevistado 13 "...Eu acho que.... Salve-se que puder!", entrevistado 01 "... na hora do desespero a gente faz coisa que...a capacidade humana não permite...". Conforme Park et. al (1946) apud Alves (2011) esse desconforto ou medo, que podem ser amplificados de acordo com a sensação do indivíduo ou a agitação social. Há uma reação circular, por exemplo, um alarme provoca a agitação social e essa agitação ocasionará no aumento da tensão dentro do grupo, que irá amplificar e contagiar as sensações dos indivíduos.

\section{CONCLUSÕES}

Através da visita exploratória, foi possível identificar problemas no projeto do Terminal Rodoviário no que se refere ao deslocamento entre pavimentos. As rampas helicoidais existentes poderão ser utilizadas como rota de fuga, conforme a sinalização existente, se isso se concretizar poderão acontecer acidentes no momento de uma evacuação. A existência as rampas se justifica pela data de inauguração do Terminal (1984), pois nessa época não era exigido tanto dos projetos no que se refere a evacuação emergencial. Nas entrevistas não é relatada pelos usuários a existência das rampas, pois em ambos os pavimentos a rota de fuga mais evidente para os entrevistados são as grandes portas, dessa forma os usuários identificaram pela espacialidade e localização as saídas de emergência do prédio e acabou não citando a existência das rampas, o que pelo ponto de vista técnico foi bem positivo.

Através das entrevistas, ficou evidente que a sinalização para rotas de fugas não é eficiente no ponto de vista dos usuários, o que poderia ser um agravante no caso de uma emergência, pois os usuários relataram que são pequenas e em pouca quantidade.

Quando questionados sobre o que procurariam de informação na sinalização (programação visual) em caso de emergência, as setas indicativas foram as mais citadas, isso demonstra que os usuários dependem de símbolos ou pictogramas que os orientem em uma situação de emergência. A percepção espacial do terminal foi positiva pelos relatos, assim podemos evidenciar que o local é de fácil entendimento pela sua conformação espacial e pela amplitude dos acessos o que facilita a identificação de possíveis rotas de fuga.

Fica evidenciado que os usuários que possuem um conhecimento prévio do local, logo se localizaram e identificaram as rotas sem auxílio da sinalização existente. Isso demonstra que a falta de treinamento nesses locais pode ser compensada com a maior frequência dos usuários em um espaço e, dessa forma auxilia na tomada de decisão e pode também diminuir o estresse em um momento de emergência. 


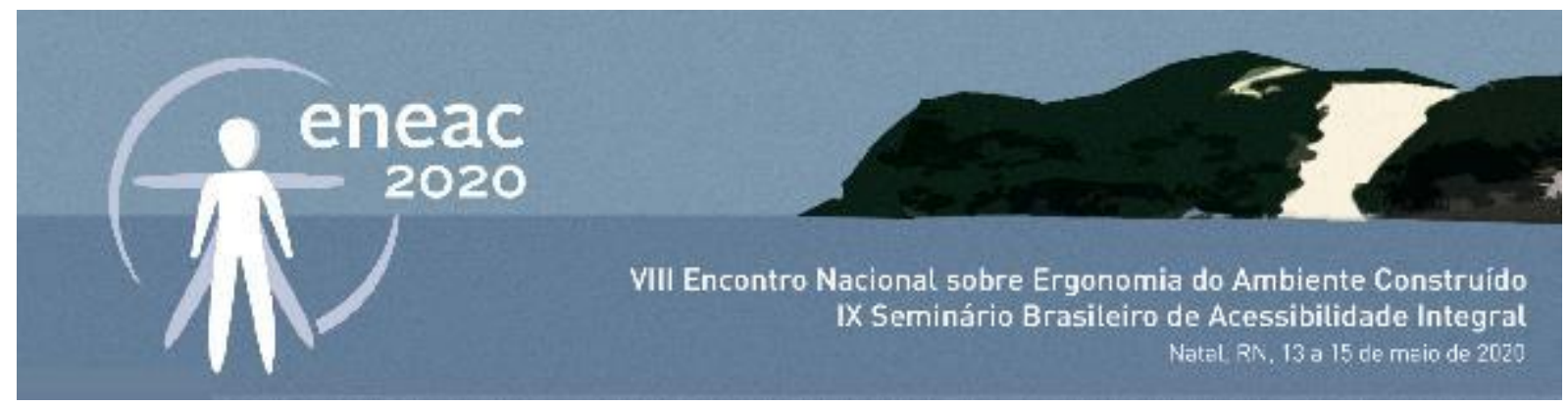

Nos relatos, onde foi identificado o possível pânico, o significado desta situação está ligada ao fator emocional dos usuários, que poderão ser potencializados em uma situação real. Isso é bastante enfatizado por autores que estudam o comportamento das multidões, onde os usuários de um espaço acabam tendo atos até mesmo primitivos para salvarem suas vidas em uma situação de emergência.

Se isso acontecer com uma parcela significativa de usuários, pode-se ter um comportamento que é chamado de agitação social e logo em seguida começa o chamado processo de milling, definida por alguns autores como a "formação de rebanhos", onde não temos mais controle sobre a ação da multidão.

Conforme os resultados pode-se afirmar que o ambiente influencia na tomada de decisão dos usuários, que tentam se localizar ou agir conforme as suas percepções, não existindo uma regra para isso. Portanto, o projeto pode sim, minimizar alguma dúvida do usuário no que e refere a orientação espacial, que poderá ser através de sinalizações efetivas indicando as rotas de fugas ou na organização espacial dos ambientes.

\section{REFERÊNCIAS}

ABRAMS, Jason Brandon, "Wayfinding in Architecture" (2010). Graduate Theses and Dissertations. http://scholarcommons.usf.edu/etd/3541

ALVES, Brunno dos P. Redes Sociais Formadas no Fenômeno do Pânico em Multidão: uma Análise via Simulação Multiagentes. Santo André, Julho - 2011. 144p. Dissertação (Mestrado Engenharia da Informação) - Programa de Pósgraduação, Universidade Federal do ABC, 2011.

BARDIN, Laurence. Análise de conteúdo. São Paulo: Edições 70, 2011, 229p

BROMBILLA, Douglas de Castro. Evacuação emergencial em locais de reunião de público. Florianópolis, 2014. 235p. Dissertação (Mestrado em Arquitetura e Urbanismo) - Programa de Pós-Graduação, UFSC, 2014.

DISCHINGER, Marta; BINS ELY, Vera Helena Moro; PIARDI, Sonia Maria Demeda Groisman. Promovendo a Acessibilidade nos Edifícios Públicos: Programa de Acessibilidade às Pessoas com Deficiência ou Mobilidade Reduzida nas Edificações de Uso Público. Florianópolis: Ministério Público de Santa Catarina, 2012.

GUERRA, Isabel Carvalho. Pesquisa qualitativa e análise de conteúdo: sentidos e formas de uso. São João do Estoril: Princípia, 2012

LYNCH, Kevin. The image of the city. Cambridge: The M.I.T. Press, 1960

ONO, Rosaria et al. Avaliação pós-ocupação: na arquitetura, no urbanismo e no design: da teoria à prática. São Paulo: Oficina de textos, 2018.

RANOYA, Guilherme; RAPOSO, Milton; SATO, Silvio Koiti; SOUZA, Sandra. Pictogramas na Comunicação de Espaços Públicos: reflexões sobre o processo do design. Revista Novos Olhares - Vol.1 N.2, 2012.

SOUZA, Ellen Priscila Nunes de. Qualidade e percepção do Ambiente Construído: Influência nas características Psicofisiológicas dos usuários. Tese (Doutorado em Arquitetura, Tecnologia e Cidade) - Campinas, SP: [s.n.], 2015.

VALENTIN, Marcos Vargas; ONO, Rosaria. Saídas de emergência e comportamento humano: uma abordagem histórica e o estado atual da arte no brasil. CONGRESSO NUTAU 2006. São Paulo, 2006. Disponível em: < http://www.Imc.ep.usp.br/grupos/gsi/wp-content/nutau/valentin.pdf>. Acesso em 27/09/2019.

WOHLWILL, J. F. (1970). The emerging discipline of environmental psychology. American Psychologist, 25, 303-312. 